\title{
Perception of assent in biomedical research among medical specialists and trainees in Abakaliki, Nigeria
}

This article was published in the following Dove Press journal:

Adolescent Health, Medicine and Therapeutics

3 October 2014

Number of times this article has been viewed

\section{Robinson Chukwudi Onoh' \\ Odidika Ugochukwu Joannes Umeora' \\ Paul Olisaemeka Ezeonu' \\ Uzoma Maryrose Agwu' \\ Lucky Osaheni Lawani' \\ Chinonyelum Thecla \\ Ezeonu ${ }^{2}$}

'Department of Obstetrics and Gynecology, ${ }^{2}$ Department of Pediatrics, Federal Teaching Hospital Abakaliki, Ebonyi State, Nigeria
Correspondence: Robinson Chukwudi Onoh

Department of Obstetrics and

Gynecology, Federal Teaching Hospital

Abakaliki, PMB 102 Abakaliki,

Ebonyi State, Nigeria

Tel +23480370075I9

Email drrobonoh@gmail.com
Background: Assent is the child's affirmative agreement to participate in research. Consent from parents and assent from children are required in research involving children.

Objective: To determine the knowledge, perception, and level of practice of assent in children among medical specialists and trainees in research work as well as the level of ethical norms observed during research.

Methods: A semistructural questionnaire was designed for a cross-sectional survey of medical specialists and trainees at the Federal Teaching Hospital Abakaliki at their different departments in the months of January and February 2013. The questionnaires were completed and analyzed.

Results: A total of 113 questionnaires were distributed, correctly completed, and analyzed. The mean age of the respondents was $36.2 \pm 5.9$ years, with a range of $25-55$ years. The mean duration of practice was $6.3 \pm 3.9$ years, with a range of 3-20 years. The majority of respondents were trainees $(106,93.8 \%)$. There was no significant association between sociodemographic variables of the respondents and the practice of obtaining assent in research involving children $(P>0.05)$. Ethical clearance was obtained by all medical specialists during their research, but none of those whose research involved children got assent from the children. The majority of medical specialists $(80 \%)$ and trainees $(65.1 \%)$ support the practice of assent as a mandatory prerequisite in ethical study. Most of the medical specialists $(83.3 \%)$ and trainees $(65.1 \%)$ agree that parents could be influenced by other considerations and benefits in enrolling their children in research. Assent after consent in research involving children in African setting was acknowledged as a necessity by $66.7 \%$ of medical specialists and $75.2 \%$ of trainees.

Conclusion: Assent was observed as a necessary ethical issue in research involving children in this study; however, it is often not sought in our setting.

Keywords: children, ethics, consent, assent

\section{Introduction}

The fundamental issue in ethical research is to ensure protection of dignity, respect of autonomy, beneficence, nonmaleficence, fairness, and legitimacy of the processes for both adults and children. ${ }^{1}$ Traditionally, children are not allowed to provide consent for themselves for medical procedures and for inclusion into research because they are hindered as a vulnerable population. ${ }^{2}$ This means they lack the necessary cognitive, psychological, or social maturity to understand the benefits and risk of the procedure or research. ${ }^{1,2}$

The United States Food and Drug Administration and the World Health Organization encourage clinical trials and research in children in order to ensure the development of safe and effective pediatric medicine. ${ }^{3}$ According to the relevant Code of Federal 
Regulation (45CFR46, Subpart b), investigators wishing to conduct clinical trials in children are required to seek consent from parents and assent from the children. ${ }^{4,5}$ The Code of Federal Regulation defines assent as the child's affirmative agreement to participate in research and stipulates that mere failure to object cannot without affirmative agreement be taken as assent. ${ }^{4}$

The age at which assent should be obtained has been recommended by the 45CFR46 and the Ethics Working Group of the Confederation of European Specialists in Pediatrics (CESP) as a responsibility of hospitals' own Institutional Review Boards (IRBs) and Independent Ethical Committees for each study or individual health care institution, respectively. ${ }^{4-6}$ However, a general convention has adopted the "rule of sevens." This rule divides a child's life into three sections: from birth to age 7; from age 7 to 14 ; and from age 14 to $21 ;^{4-7}$ it states that children under the age of 7 lack the capacity to make their own decisions, while children from 7 to 14 are presumed not to have this capacity until proven otherwise, and children over 14 years of age are presumed to have decision-making capacity unless proven otherwise. It has been recommended that a flexible approach should be adopted, and that there may be exceptions to the rule of seven. ${ }^{89}$ All children, even those not judged as competent to make decisions for themselves, have a right to receive information given to them in a way that they can understand and could give their assent or dissent. ${ }^{10,11}$ In addition, the importance of protecting children from harm suggests that the sustained dissent of all children, including those who are unable to provide assent, should be respected. ${ }^{11}$ On the other hand, children younger than 18 years of age are minors and perhaps could not give assent depending on the maturity and psychological state of the person involved. ${ }^{11}$ In fact, the requirements for children participating in clinical trials are somewhat indistinct, variations both between countries and within countries. ${ }^{11}$

In reviewing research with children as subjects, in addition to ensuring adherence to the general regulatory requirements of 45 CFR 46, Subpart A, the IRB also must consider the potential benefits, risks, and discomforts of the research to children and assess the justification for their inclusion in the research. ${ }^{12,13}$ In assessing the risks and potential benefits, the IRB should consider the child's health status, age, and ability to understand what is involved in the research as well as potential benefits to subjects, other children with the same disease or condition, or society as a whole. ${ }^{12-14}$

The Health and Human Services (HHS) regulations at 45 CFR 46, subpart D permit IRBs to approve three categories of research involving children as subjects. These include 45 CFR 46.404 (research not involving greater than minimal risk to the children), 45 CFR 46.405 (research involving greater than minimal risk but presenting the prospect of direct benefit to the individual child subjects involved in the research), and 45 CFR 46.406 (research involving greater than minimal risk and no prospect of direct benefit to the individual child subjects involved in the research, but likely to yield generalizable knowledge about the subject's disorder or condition). ${ }^{12,13} \mathrm{~A}$ fourth category of research requires a special level of HHS review beyond that provided by the IRB. This is the 45 CFR 46.407 (research that the IRB believes does not meet the conditions of 45 CFR 46.404, 46.405, or 46.406, but which presents a reasonable opportunity to further the understanding, prevention, or alleviation of a serious problem affecting the health or welfare of children) and is reviewed by the HHS secretary or his/her designee. ${ }^{12,13}$ In all these, adequate provisions are made for soliciting the assent of the children and the permission of their parents or guardians, as set forth in HHS regulations at 45 CFR 46.408. ${ }^{12,13}$

Assent demonstrates respect for the child and his/her developing autonomy. In order to give meaningful assent, the child must understand that procedures will be performed, voluntarily choose to undergo the procedures, and communicate this choice. ${ }^{15}$ Understanding the elements of informed consent has been the paradigm for assessing capacity to give assent. $^{15}$

We therefore wish to determine the knowledge, perception, and level of practice of obtaining assent in children among medical specialists and trainees in research work as well as the level of ethical norms observed during research.

\section{Materials and methods}

This study was done at the Federal Teaching Hospital in Abakaliki Ebonyi State, Nigeria. Federal Teaching Hospital Abakaliki is a major tertiary health facility located in the capital city of the state and receives referrals from all over the state, from neighboring states, and from other parts of Nigeria. It is an accredited center for postgraduate residency training in almost all aspects of medicine and surgery. It is also accredited for training of medical and paramedical undergraduates. There is a functional research and ethics committee at Federal Teaching Hospital Abakaliki.

The study was a cross-sectional description study. A semistructured questionnaire was administered to medical specialists and trainees at Federal Teaching Hospital Abakaliki in the months of January and February 2013. The questionnaire was pretested and validated at the Department of 
Obstetrics and Gynecology among the medical specialists and trainees. Written consent was obtained from the respondents before completion of the questionnaire. The questionnaires were administered by two trained research assistants to the consenting medical specialist and trainee in their respective departments within the study period.

Ethical approval for the study was given by the ethics and research committee of Federal Teaching Hospital Abakaliki. The sociodemographic variables of the participants, their perception, and practice of obtaining assent in research work were obtained.

Information gathered from the participants was entered into the computer using EPI Info version 3.5.1 statistical software (Atlanta, GA, USA), and this was used for data analysis. Univariate analysis was done to determine the descriptive analysis of the sociodemographic characteristic and other variables.

Bivariate and multivariate analyses were done by stratification of variables, and this was used to determine level of associations. Multivariate analysis by logistic regression was used to determine level of association between the sociodemographic variables and the practice of obtaining assent. The level of significance was set at $P<0.05$.

\section{Results}

A total of 113 questionnaires were correctly completed and analyzed. The mean age of respondents was $36.2 \pm 5.9$ years, with a range of $25-55$ years. The mean duration of practice was $6.3 \pm 3.9$ years, with a range of 3-20 years. The majority of respondents were trainees $(106,93.8 \%)$. All the medical practitioners who were 50 years of age and older (100\%) indicated they did not obtain assent in their research involving children. The majority of the respondents within the age brackets of $20-29$ years $(5,71.4 \%), 30-39$ years $(35,64.8 \%)$, and 40-49 years $(9,60 \%)$ did not obtain assent in their research involving children. All the specialists $(3,100 \%)$ and the majority of the trainees $(48,64 \%)$ did not obtain assent in their research involving children. Among respondents who conducted research involving children, most of the unmarried medical practitioners $(8,53.3 \%)$ obtained assent, while the majority of the married medical practitioners (44, 69.8\%) did not obtain assent during the research. The majority of the doctors who had children $(40,72.7 \%)$ did not obtain assent in conducting research involving children, while most of the respondents who did not have children $(12,52.2 \%)$ obtained assent in conducting research involving children. Most of the medical doctors who had conducted research involving children from the departments of Obstetrics and
Gynecology $(13,65 \%)$, Pediatrics (7, 53.8\%), Internal Medicine (11, 73.3\%), Surgery (5, 62.5\%), and Family Medicine and Community Medicine (3, 75\%) did not obtain assent from children during the research. Most of the doctors who had practiced for more than 10 years $(73.3 \%)$ did not obtain assent while conducting research involving children. Assent was also not obtained by the majority of respondents who had practiced for a period of 6-10 years $(14,63.6 \%)$ and $0-5$ years $(26,63.4 \%)$ during their research in children (Table 1).

Table 2 shows the adjusted odds ratio of the sociodemographic variables and the practice of obtaining assent among specialists and trainees. There was no significant association between sociodemographic variables of the respondents and the practice of obtaining assent in research involving children $(P>0.05)$.

Table 3 shows the perception of biomedical research in children among specialists and trainees. The majority of respondents $(90,80.4 \%)$ have been involved in some type of biomedical research. All the specialists (100\%) who were recruited for this study have been involved in biomedical research, while the majority of the trainees $(83,79 \%)$ have been involved in biomedical research. Most respondents $(67,72.8 \%)$ obtained ethical approval for their research work by the appropriate research and ethic committee before conducting their research. Among these respondents, all specialists $(100 \%)$ and the majority of the trainees $(62,71.3 \%)$ conducted their research work with ethical approval. Among all that have done research involving children, none of the specialists obtained assent, while $(27,36 \%)$ of the trainees obtained assent for their study. The majority of the participants $(77,77.8 \%)$ indicated that they were aware of assent as a mandatory prerequisite in an ethical study, with specialists $(4,80 \%)$ and trainees $(73,77.7 \%)$ constituting this majority. Most specialists $(5,83.3 \%)$ and trainees $(70,74.5 \%)$ affirmed that assent should be for a particular age group. Assent was judged as a necessity after consent from parents in an African setting by most of the respondents (80, 74.8\%), with the majority of the specialists $(4,66.7 \%)$ and trainees $(75.2 \%)$ supporting this affirmation. Most of the specialists $(5,83.3 \%)$ and trainees $(86,85.1 \%)$ feel that the benefits and/or disadvantages of the research could influence parents in enrolling their children for research instead of the best interest of the child.

The most common reason given by respondents for not obtaining assent from children during research involving children was that their research was retrospective. Other reasons given include the perception that consent from 
Table I Sociodemographic variables and the practice of assent among specialists and trainees

\begin{tabular}{|c|c|c|c|}
\hline Variable & Number (\%) (n=768) & $\begin{array}{l}\text { Obtained assent } \\
\text { during research } n(\%)\end{array}$ & $\begin{array}{l}\text { Did not obtain assent } \\
\text { during research } n(\%)\end{array}$ \\
\hline \multicolumn{4}{|l|}{ Age (years) } \\
\hline $20-29$ & $12(10.6)$ & $2(28.6)$ & $5(7 I .4)$ \\
\hline $30-39$ & $76(67.3)$ & $19(35.2)$ & $35(64.8)$ \\
\hline $40-49$ & $23(20.4)$ & $6(40)$ & $9(60.0)$ \\
\hline$>50$ & $2(1.8)$ & $0(0)$ & $2(100)$ \\
\hline \multicolumn{4}{|l|}{ Status of doctors } \\
\hline Specialists & $7(6.2)$ & 0 & $3(100)$ \\
\hline Trainees & $106(93.8)$ & $27(36.0)$ & $48(64.0)$ \\
\hline \multicolumn{4}{|l|}{ Marital status } \\
\hline Married & $88(77.9)$ & $19(30.2)$ & $44(69.8)$ \\
\hline Single & $25(22.1)$ & $8(53.3)$ & $7(46.7)$ \\
\hline \multicolumn{4}{|l|}{ Have children } \\
\hline Yes & $74(65.5)$ & I5 (27.3) & $40(72.7)$ \\
\hline No & $39(34.5)$ & $12(52.2)$ & II (47.8) \\
\hline \multicolumn{4}{|l|}{ Department } \\
\hline Obstetrics and Gynecology & $24(23.1)$ & $7(35)$ & $13(65)$ \\
\hline Pediatrics & $17(16.3)$ & $6(46.2)$ & $7(53.8)$ \\
\hline Internal Medicine & $27(26.0)$ & $4(26.7)$ & II (73.3) \\
\hline Surgery & $19(36.4)$ & $4(36.4)$ & $7(63.6)$ \\
\hline Family medicine & II (10.6) & $3(37.5)$ & $5(62.5)$ \\
\hline Community medicine & $6(5.8)$ & I (25) & $3(75.0)$ \\
\hline \multicolumn{4}{|l|}{ Duration of practice (years) } \\
\hline $0-5$ & $58(5 । .3)$ & $15(36.6)$ & $26(63.4)$ \\
\hline $6-10$ & $33(29.2)$ & $8(36.4)$ & $14(63.6)$ \\
\hline$>10$ & $22(19.5)$ & $4(26.7)$ & II (73.3) \\
\hline
\end{tabular}

parents was adequate $(13,31.7 \%)$, assent was not necessary $(9,22 \%)$, and obtaining assent was difficult in children $(1,2.4 \%)$ (Table 4$)$. The reasons given by the respondents who support that assent should not be made mandatory include the feeling that the parent's choice is perfect for the children $(9,32.1 \%)$, some children might not understand the details of the research $(8,28.6 \%)$, seeking assent is not culturally African $(6,21.4 \%)$, and that children are not independent of the family $(5,17.9 \%)$ (Table 5).

Ethical clearance was obtained by all medical specialists during their research, but none of those whose research involved children got assent from the children. The majority of the medical specialists ( $80 \%$ ) and trainees (65.1\%) support the practice of obtaining assent as a mandatory prerequisite in ethical study. Assent after consent in research involving children in African setting was acknowledged as a necessity by $66.7 \%$ of medical specialists and $75.2 \%$ of trainees.

\section{Discussion}

Assent is a topical, controversial, and revolutionizing concept in research involving children, especially in developing countries. It has been recognized that involving children

Table 2 Association between sociodemographic variables and the practice of assent among specialists and trainees

\begin{tabular}{|c|c|c|c|c|c|c|c|}
\hline \multirow[t]{2}{*}{ Variable } & \multirow[t]{2}{*}{ Odds ratio } & \multicolumn{2}{|c|}{$95 \% \mathrm{Cl}$} & \multirow[t]{2}{*}{ Coefficient } & \multirow[t]{2}{*}{ SE } & \multirow[t]{2}{*}{ Z-statistic } & \multirow[t]{2}{*}{$P$-value } \\
\hline & & (Lower) & (Upper) & & & & \\
\hline Age & $1.056 \mathrm{I}$ & 0.9373 & 1.1899 & 0.0546 & 0.0609 & 0.8968 & 0.3698 \\
\hline Status of doctor & $436,738.00$ & 0.0000 & $>1.0 \mathrm{EI} 2$ & |2.987| & $287.560 \mathrm{I}$ & 0.0485 & 0.9613 \\
\hline Marital status & 1.0923 & 0.1270 & 9.3939 & 0.0883 & 1.0979 & 0.0804 & 0.9359 \\
\hline Have had children & 0.1896 & 0.0237 & 1.5144 & -1.6629 & 1.0602 & -1.5685 & 0.1168 \\
\hline Department of Pediatrics & 1.4698 & 0.2763 & $7.817 \mid$ & 0.3851 & 0.8527 & 0.4516 & 0.6515 \\
\hline Internal Medicine & 0.4838 & 0.0873 & 2.6819 & -0.7261 & 0.8738 & 0.8310 & 0.4060 \\
\hline Surgery & 1.1931 & 0.2249 & 6.3279 & 0.1765 & 0.8513 & 0.2074 & 0.8357 \\
\hline Family medicine & 1.0697 & 0.1574 & 7.2695 & 0.0674 & 0.9777 & 0.0689 & $0.945 I$ \\
\hline Community medicine & 0.7722 & 0.0568 & 10.4919 & -0.2585 & 1.3312 & -0.1942 & 0.8446 \\
\hline Constant & & & & -14.6878 & 267.5726 & -0.0549 & 0.9562 \\
\hline
\end{tabular}

Abbreviations: $\mathrm{Cl}$, confidence interval; $\mathrm{SE}$, standard error. 
Table 3 Perception and practice of biomedical research among medical specialist and trainees in children

\begin{tabular}{|c|c|c|c|}
\hline Variable & Total number (\%) & Specialists (\%) & Trainees (\%) \\
\hline \multicolumn{4}{|c|}{ Involvement in any research } \\
\hline Yes & $90(80.4)$ & $7(100)$ & $83(79)$ \\
\hline No & $22(19.6)$ & 0 & $22(21)$ \\
\hline \multicolumn{4}{|c|}{ Research done approved by ethics committee } \\
\hline Yes & $67(72.8)$ & $5(100)$ & $62(71.3)$ \\
\hline No & $25(27.2)$ & 0 & $25(28.7)$ \\
\hline \multicolumn{4}{|c|}{ Research involving children } \\
\hline Yes & $33(33.0)$ & I (I4.3) & $32(34.4)$ \\
\hline No & $67(67.0)$ & $6(85.7)$ & $61(65.6)$ \\
\hline \multicolumn{4}{|c|}{ Obtained assent from children } \\
\hline Yes & $27(34.6)$ & 0 & $27(36)$ \\
\hline No & $51(65.4)$ & $3(100)$ & $48(64)$ \\
\hline \multicolumn{4}{|c|}{ Awareness on assent as a mediatory prerequisite in an ethical study } \\
\hline Yes & $77(77.8)$ & $4(80)$ & $73(77.7)$ \\
\hline No & $22(22.2)$ & I (20) & $21(22.3)$ \\
\hline \multicolumn{4}{|c|}{ Should assent be for a particular age group } \\
\hline Yes & $75(75)$ & $5(83.3)$ & $70(74.5)$ \\
\hline No & $25(25)$ & $I(16.7)$ & $24(25.5)$ \\
\hline \multicolumn{4}{|c|}{ Is assent necessary after consent from parents in African family setting } \\
\hline Yes & $80(74.8)$ & $4(66.7)$ & $76(75.2)$ \\
\hline No & $27(25.2)$ & $2(3.33)$ & $25(24.8)$ \\
\hline \multicolumn{4}{|c|}{$\begin{array}{l}\text { Could benefits/disadvantage influence parents on enrolling their children } \\
\text { for research instead of the best interest of the child }\end{array}$} \\
\hline Yes & $91(85.0)$ & $5(83.3)$ & $86(85.1)$ \\
\hline No & $16(15.0)$ & I (I6.7) & 15 (14.9) \\
\hline
\end{tabular}

in research raises serious ethical concerns, due largely to their reduced autonomy and children's incompetency to give informed consent. Nevertheless, it is believed that simply restricting children's participation in research is not appropriate because conduct of research involving children is necessary for the development of new treatment or preventive methods, and also to protect children from unvalidated practices which may be harmful. ${ }^{12,13}$ Related issues include at which age to obtain assent and at which age to change from assent to consent. There are several opinions on the rule of seven and minor children; several guidelines state that assent should be obtained where children have sufficient understanding and intelligence to understand what is proposed, and that this ability could be determined taking into consideration the child's age, maturity, and psychological state. ${ }^{8,12,13}$

Table 4 Reasons for not supporting obtaining assent from children

\begin{tabular}{lll}
\hline Reasons (variables) & $\begin{array}{l}\text { Total number } \\
(\mathbf{n = 4} \text { I) }\end{array}$ & $\%$ \\
\hline Not necessary & 9 & 22 \\
Feel consent from parents is adequate & 13 & 31.7 \\
Was difficult getting assent from children & 1 & 2.4 \\
Study was retrospective & 18 & 43.9 \\
\hline
\end{tabular}

Table 5 Reasons why assent should not be made mandatory

\begin{tabular}{lll}
\hline Reasons (variables) & Total number $(\mathbf{n = 2 8 )}$ & $\%$ \\
\hline $\begin{array}{l}\text { Children are not independent } \\
\text { of the family }\end{array}$ & 5 & 17.9 \\
$\begin{array}{l}\text { Parental choice is acceptable } \\
\text { for the children }\end{array}$ & 9 & 32.1 \\
$\begin{array}{l}\text { Some children cannot } \\
\text { understand details of research }\end{array}$ & 8 & 28.6 \\
\begin{tabular}{l} 
Seeking assent is not African \\
\hline
\end{tabular} & 6 & 21.4 \\
\hline
\end{tabular}

In this study, assent was obtained by $36 \%$ of the medical doctors who had conducted research involving children; none of those who obtained assent was a specialist. The reasons why specialists do not obtain assent in research could be attributed to the fact that most specialists have children and feel they should decide for their children, while trainees are young doctors who are not married and are likely to be in tune with the guidelines for research in children. This is buttressed by the reasons given for not obtaining assent in prospective research involving children in this study, which was mainly that a parent's consent was adequate. Other reasons were that assent was not necessary, and that it was difficult obtaining assent from children. The ethics committees (EC)/IRBs have the challenging and difficult responsibility of ensuring that children, who constitute a vulnerable population, are not used as a commodity in clinical research in absence of explicit national guidelines for pediatric research and in the milieu of abject poverty. ${ }^{2}$ It is also the responsibility of the EC/IRB to take care that the participation of children in research is without coercion or inducement. ${ }^{2,12-14}$ In this study, the majority of the research work was approved by the Research and Ethics Committee of our institution; however, assent was not obtained in most research involving children. This buttresses the fact that there is a need for update courses for the members of the Research and Ethics Committee to ensure that they enforce the rules and regulations guiding research in children.

Most specialists and trainees in this research feel that assent should be obtained for children of a particular age. There have been varying opinions on the appropriate age to obtain assent and when to convert to consent. The American Academy of Pediatrics expects that assent be obtained from children over the age of 7 years in pediatric practice. ${ }^{6}$ There have been arguments favoring a much higher cut-off age of 14 years for pediatric research trials. ${ }^{7}$ The age at which assent is sought has both practical and theoretical implications. Practically, setting a chronological age at which assent must be obtained allows clear direction for implementing an assent process. ${ }^{5}$ However, as we noted above, the age 
thresholds set by IRBs can range widely across institutions and across protocols. ${ }^{10}$ Obtaining assent at 7 years of age and older is relatively common, but the primary defense for this position is the rule of sevens that originated in the 1300s. ${ }^{11}$ There have been arguments on the validity of this rule, since its long history does not necessarily mean it is developmentally appropriate to use to determine pediatric assent practices, nor does the rule even clearly support asking for assent after age 7.,11 Moreover, studies of children's understanding of clinical trials provide evidence that the threshold should be set at 9 years or at 11 years. ${ }^{13}$ Children younger than 18 years of age have been called minors and could give assent depending on the maturity and psychological state of the person involved.,11 In addition to the crucial concept of age, a number of other factors can influence a child's ability to give assent. ${ }^{5}$ These factors include maturity, the psychological state of the child, the child's medical diagnosis, the child's role and relationships with others, as well as the perceived impact of disagreeing with important figures. ${ }^{6-16}$ In addition, factors such as who is asked to obtain assent and whether the child has previous experience with research can sway the child's decision of assent or dissent without consideration of the risks and benefits. ${ }^{5}$ The age at which assent should be obtained has been recommended by the 45CFR46 and the Ethics Working Group of CESP as a responsibility of hospitals' own IRBs/ Independent Ethical Committees for each study or individual health care institution, respectively. ${ }^{1-6}$

Most parents act in the best interests of their children on most occasions. However, given the magnitude of poverty prevalent in some countries, it is possible that financial benefits provided as compensation for participation could act as inducement and influence parental judgment regarding enrolling the child in a research. Most of the medical specialists and trainees in this study agree that parents could be influenced by other considerations and benefits in enrolling their children in research. According to the relevant Code of Federal Regulation (45CFR46, Subpart b), investigators wishing to conduct clinical trials in children are required to seek consent from parents and assent from the children. ${ }^{4,12,13}$ The EC/IRB have additional responsibilities while dealing with these studies by probing the potential risks and benefits of a trial in children and adolescents. ${ }^{12-14}$ They should also monitor the process of obtaining assent to ensure that developmentally appropriate information is being provided to children before requesting their assent, that their dissent is respected, and that their participation is entirely voluntary. ${ }^{11}$ Going beyond their usual role, the EC/IRB should also take up the mantle of an educator, informing researchers about the ethical standards to be followed while conducting pediatric trials. Only with such affirmative action would the EC/IRB be able to fulfill their mandated role of safeguarding the interests of children and adolescents participating in research trials. ${ }^{14}$

\section{Conclusion}

In conclusion, assent was observed as a necessary ethical issue in research involving children in this study; however, its practice is still very poor in our setting. There is also fair knowledge on the rules and regulation guiding obtaining assent in research involving children.

We recommend the establishment of research and ethics committee in all institutions so that all institutions could develop guidelines on research, especially with respect to assent in research involving children. There should also be regular reviews of such regulatory bodies as well as further training and updates on the advances in ethics and research.

An important limitation of this study is that it was done in one teaching hospital in Nigeria and as such may not truly reflect what happens in Nigeria.

\section{Acknowledgments}

We wish to acknowledge the management of Federal Teaching Hospital Abakaliki Ebonyi State Nigeria for their support in carrying out this research. We are also grateful to the resident doctors who assisted in data collection and the research unit of Federal Teaching Hospital Abakaliki for the secretarial work.

\section{Disclosure}

The authors declare no conflicts of interest in this work.

\section{References}

1. The National Commission for the Protection of Human Subjects of Biomedical and Behavioral Research Research. Research involving children: reports and recommendations. Washington DC; Department of Health, Education and Welfare; 1977.

2. Bavdekar SB. Protecting children participating in research. Indian Pediatr. 2006;43(2):180-181.

3. World Health Organization (WHO). Hand book for Good Clinical Research Practice (GCP): Guidance for implementation. Geneva: WHO; 2002. Available at: http://apps.who.int/prequal/info_general/documents/ GCP/GCP_handbook.pdf. Accessed August 29, 2014.

4. United States Department of Health and Human Services (DHHS), National Institutes of Health and Office for Human Research Protection. Code of Federal Regulations, Title 45 Public Welfare, part 46 Protection of Human Subjects (2009). Available at: http://www.hhs.gov/ohrp/ humansubjects/guidance/45cfr46.html. Accessed August 29, 2014.

5. Vreeman RC, Nyandika WM, Meslim EM. Paediatric assent for a study of antiretroviral therapy dosing for children in western Kenya: A case study in International Research Collaboration. J Empir Res Hum Res Ethics. 2009;4(1):3-16. 
6. [No authors listed] Informed consent, parental permission, and assent in pediatrics practice. Pediatrics. 1995;95(2):314-317.

7. Wendler D, Shah S. Should children decide whether they are enrolled in nonbeneficial research? Am J Bioeth. 2003;3(4):1-7.

8. McIntosh N, Bates P, Brykczynska G, et al. Guideline for the ethical conduct of medical research involving children. Royal College of Pediatrics and ChildHealth: Ethics Advisory Committee. Arch Dis Child. 2000;82(2):177-182.

9. Ungar D, Joffe S, Kodish E. Children are not small adults: documentation of assent for research involving children. $J$ Pediatr. 2006;149(Suppl 1):S31-S33.

10. Kimberly MB, Hoehn KS, Feudtner C, Nelson RM, Schreiner M. Variation in standards of research compensation and child assent practices: a comparison of 69 institutional review board-approved informed permission and assent forms for 3 multicenter pediatric clinical trials. Pediatrics. 2006;117(5):1706-1711.

11. Wendler DS. Assent in paediatric research: theoretical and practical considerations. J Med Ethics. 2006;32(4):229-234.

12. Efficacy Guidelines: ICH Clinical investigation of medicinal products in the paediatric population, (ICH-11). Geneva, International conference on harmonization of technical requirement for registration of pharmaceuticals for human use, Jul 2000. Available at: http://www.ich.org/ fileadmin/Public_Web_Site/ICH_Products/Guidelines/Efficacy/E2F/ Step4/E2F_Step_4.pdf. Accessed August 29, 2014.
13. Paediatric clinical trials guidiance for assessors [webpage on the Internet]. World Health Organization, June 2011. Available at: http:// www.who.int/childmedicines/CTguidance.pdf. Accessed August 29, 2014.

14. International ethical guidelinesfor biomedical research involving human subjects [webpage on the Internet]. Council for International Organizations of Medical Scieces (CIOMS) and World Health Organization (WHO), Geneva 2002. Available at: http://www.cioms. ch/publications/layout_guide2002.pdf. Accessed August 29, 2014.

15. Rossi WC, Reynolds W, Nelson RM. Child assent and parental permission in pediatric research. Theor Med Bioeth. 2003;24(2): 131-148.

16. Tait AR, Voepel-Lewis T, Malviya S. Do they understand? (part II): assent of children participating in clinical anesthesia and surgery research. Anesthesiology. 2003;98(3):609-614.
Adolescent Health, Medicine and Therapeutics

\section{Publish your work in this journal}

Adolescent Health, Medicine and Therapeutics is an international, peer-reviewed, open access journal focusing on health, pathology, and treatment issues specific to the adolescent age group. All aspects of health maintenance, preventative measures and disease treatmen interventions are addressed within the journal and practitioners from

\section{Dovepress}

all disciplines are invited to submit their work as well as healthcare researchers and patient support groups.. The manuscript management system is completely online and includes a very quick and fair peerreview system. Visit http://www.dovepress.com/testimonials.php to read real quotes from published authors.

Submit your manuscript here: http://www.dovepress.com/adolescent-health-medicine-and-therapeutics-journal 